\title{
Condicionantes dos gastos com pessoal nos municípios do Ceará: efeito composição e mudança prematura de prefeito
}

Conditions of personnel costs in the municipalities of Ceará: composition effect and premature change of mayor

\author{
Vanessa Aragão de Goes Salgueiro ${ }^{1}$ \\ Ricardo Brito Soares ${ }^{2}$ \\ Manuel Salgueiro Rodrigues Júnior ${ }^{3}$
}

\section{RESUMO}

Desde a edição da Lei de Responsabilidade Fiscal, os entes públicos brasileiros estão sujeitos a limitações nos gastos, entre eles, as despesas com pessoal. Entretanto, vários fatores influenciam o aumento desses gastos, como os ciclos políticos, regras fiscais rigorosas e condições socioeconômicas. Esta pesquisa investiga, além desses fatores, como a composição dos funcionários e a mudança prematura de prefeito afetam os gastos com pessoal como proporção da Receita Corrente Líquida. Para isso, a pesquisa utiliza informações dos 184 municípios do Ceará do interstício político de 2013 a 2016 e um modelo de regressão linear com dados agrupados. Os resultados apontam que a mudança prematura de prefeito e o percentual de servidores efetivos são variáveis significantes e contribuem positivamente para o aumento da despesa com pessoal. Portanto, prefeitos substitutos não tendem a implementar ajustes de despesas com pessoal; pelo contrário, adicionam ainda mais na folha de pagamento, com riscos maiores de irregularidades.

\footnotetext{
1 Mestre em Economia pela Universidade Federal do Ceará (UFC). Analista de Controle Externo do Tribunal de Contas do Estado do Ceará. E-mail: vn.goes@gmail.com.

$2 \quad \mathrm{PhD}$ em Economia pela University of New Hampshire. Professor do CAEN/UFC. E-mail: ricardosoares@caen.ufc.br.

3 Doutor em Administração e Controladoria pela Universidade Federal do Ceará (UFC). Professor da Universidade Estadual do Ceará (UECE). Analista de Controle Externo do Tribunal de Contas do Estado do Ceará. E-mail: msrodriguesjr@gmail.com.
} 
Palavras-chave: Despesa com pessoal. Lei de Responsabilidade Fiscal. Mudança prematura de prefeito. Proporção de servidores. Ciclos político-econômicos.

\section{ABSTRACT}

Since the edition of the Fiscal Responsibility Law, Brazilian public entities have been subject to spending limitations, including personnel costs. However, several factors influence the increase of these expenditures, such as political cycles, strict fiscal rules and socioeconomic conditions. We investigate, in addition to these factors, how the composition of employees and the premature change of mayor affect personnel costs as a proportion of Net Current Revenue. For this, we use information from the $184 \mathrm{mu}-$ nicipalities of Ceará from the political interstice from 2013 to 2016 and a linear regression model with grouped data. The results show that the premature change of mayor and the percentage of effective civil servants are significant variables and contribute positively to the increase in personnel costs. Therefore, substitute mayors do not tend to implement personnel costs adjustments; on the contrary, they add even more to the payroll, with greater risks of irregularities.

Keywords: Personnel costs. Fiscal Responsibility Law. Premature change of mayor. Proportion of public civil servants. Political-economic cycles.

Recebido: 05-02-2021

Aprovado: 16-03-2021

\section{INTRODUÇÃO}

A Lei de Responsabilidade Fiscal (LRF), instituída em 2000, exerce papel fundamental nas finanças públicas brasileiras. A partir da definição dos pilares que devem nortear a condução da responsabilidade fiscal dos governantes, essa legislação se tornou um marco e, portanto, fomentou vários estudos em torno de seus ditames. 
Um dos pilares observados na estrutura da LRF reporta atenção aos aspectos de controle das despesas públicas, estabelecendo restrições para os gastos públicos; entre os quais, foram registrados parâmetros limitadores para a Despesa Total com Pessoal. Essa questão já foi objeto de estudo de pesquisas acadêmicas que retratam desde o simples cumprimento do patamar previsto na legislação (GIUBERT, 2005; ALVES et al., 2015; SILVA, 2018) até a análise de determinantes para a elevação dos gastos com pessoal (AZEVEDO et al., 2015; BARRETO; MENDONÇA, 2010) e de fatores que levam ao descumprimento do previsto na legislação (CRUZ; MACEDO; SAUERBRONN, 2013).

Importante frisar que a teoria dos ciclos político-econômicos indica que os gastos públicos podem variar a partir dos interesses eleitorais dos governantes, expandindo as despesas em um período pré-eleitoral e retraindo-as em outros momentos (DOWNS, 1957; NORDHAUS, 1975; ROGOFF, 1990). A perspectiva de reeleição pode influenciar o comportamento do prefeito ao longo de todo o primeiro mandato, aumentando gastos nesse período e contendo-os em um segundo mandato (OLIVEIRA et al., 2017; KUTIANSKI; SCARPIN, 2014; SAKURAI; MENEZES-FILHO, 2008). Nesse contexto, inclui-se a despesa com pessoal, que é o objeto do presente estudo.

O controle das ações governamentais, exercido no âmbito externo pelos Tribunais de Contas, é inerente à administração pública e auxilia no importante papel de garantir a supremacia do interesse coletivo. Repousa, também, sobre a atividade de controle a responsabilidade de mitigar o conflito apontado pela teoria da agência (prevista inicialmente por Jensen e Meckling para o ambiente empresarial), entre o gestor público (agente), que tem responsabilidade de promover o bem-estar do cidadão (principal), mas que tem liberdade para adotar comportamentos que atendam tão somente aos seus interesses particulares. Nessa esteira, é importante ressaltar, ainda, que o cidadão (principal) tem dificuldade de acompanhar as ações ao gestor público (agente), gerando assimetria informacional (SLOMSKI, 2009). 
Nesse sentido, a Constituição Federal Brasileira (CF/88) prevê que o controle deve ser exercido tanto internamente, desempenhado usualmente pelas controladorias de cada órgão ou Poder, quanto externamente, pelos Tribunais de Contas. No formato previsto constitucionalmente, os Tribunais de Contas, por serem órgãos fora da estrutura do ente auditado, devem atuar com maior transparência e credibilidade.

Com base nesse pressuposto, esta pesquisa optou por se debruçar sobre os apontamentos destacados nos Relatórios Iniciais das Prestações de Contas de Governo, emanados pelo órgão de controle externo, dos exercícios de 2013 a 2016, e, em especial, identificando a evolução do percentual de gastos com pessoal sobre a receita corrente líquida (RCL) em cada município, atentando para a eventual inobservância do já destacado limite de despesa com pessoal.

Ademais, tendo em vista a variedade de corte de contas existentes no país, optou-se por fazer um recorte territorial, selecionando uma subunidade da federação. Portanto, foram escolhidos os municípios do estado do Ceará.

\section{PROBLEMA DE PESQUISA E OBJETIVO}

A partir do levantamento inicial, pretende-se analisar a influência de aspectos políticos e eleitorais, bem como a proporção dos servidores do município sobre a flutuação do percentual da despesa com pessoal sobre a RCL dos municípios, o que caracteriza o objetivo geral do trabalho.

Esta pesquisa busca investigar como determinadas características políticas e socioeconômicas dos municípios e de seus respectivos prefeitos podem impactar nessa despesa com pessoal, que é um dos maiores gastos entre as despesas correntes (BARRETO; MENDONÇA, 2010). Em meio aos vários fatores que podem influenciar já apontados na literatura, este trabalho destaca, em sua contribuição, a própria proporção do pessoal (efetivos, comissionados, estagiários, prestação de serviços) em relação aos funcionários do Poder Executivo do município e a ocorrência de mu- 
dança de prefeito no decorrer do mandato no município.

Tratando-se do impacto da composição do pessoal, espera-se que $o$ aumento da proporção dos servidores efetivos, em relação aos funcionários do Poder Executivo do município, influencie no aumento do percentual da despesa com pessoal em relação à receita líquida. Da mesma forma, entende-se que o aumento da proporção dos comissionados reflete no aumento desse percentual.

No que concerne à mudança de prefeito antes do término do mandato, o substituto pode ser mais preventivo, evitando aumentar gastos ou cometer irregularidades. Entretanto, pode ocorrer um aumento no percentual da despesa com pessoal; isso pela possibilidade de o prefeito anterior já ter deixado resultados negativos na sua gestão, acrescido de eventual anseio pela reeleição do atual prefeito empossado, que tenderia a aumentar as suas despesas.

Os impactos esperados de tais variáveis são abordados com maior profundidade no referencial teórico, assim como o detalhamento da variável dependente. Em seguida, a metodologia de estimação para explicar os efeitos, bem como o detalhamento da base de dados, é descrita na terceira seção. A análise e a inferência sobre os resultados constam na seção quatro.

\section{REFERENCIAL TEÓRICO}

\subsection{O CONTROLE DOS GASTOS COM PESSOAL PELO TRIBUNAL DE CONTAS E A LRF}

A necessidade de acompanhamento e controle, na utilização dos recursos públicos, é notória diante de constantes relatos de corrupção e má gestão pública.

Os Tribunais de Contas, entes responsáveis pela realização do controle dos bens e recursos públicos, apreciam as prestações de contas de governo que lhes são encaminhadas pelos gestores. No âmbito do estado 
do Ceará, no caso dos municípios, o Tribunal de Contas dos Municípios exercia essa atividade; entretanto, com a sua extinção, em 2017, suas funções foram absorvidas pelo Tribunal de Contas do Estado do Ceará.

Assim, decorrente de sua operação, são detectadas falhas ocasionadas pela má gestão pública e pelo descumprimento de preceitos legais e constitucionais, que podem gerar ambiente propício para a corrupção caso não sejam apontadas.

E, nesse contexto, em pesquisa realizada por Kruger, Krombauer e Sousa (2012), verificou-se que a Lei de Responsabilidade Fiscal (LRF - Lei Complementar $n^{\circ} 101 / 2000$ ) foi determinante nas ações de controle externo e no aumento da quantidade de falhas identificadas.

Também em pesquisa realizada por Crisóstomo, Cavalcante e Freitas (2015), em uma amostra de contas de governo das prefeituras da região metropolitana de Fortaleza, foi apontado que a LRF era uma importante ferramenta de apoio aos Tribunais de Contas.

Giuberti (2005) ressalta que a Lei de Responsabilidade Fiscal (LRF) não se detém a apenas estabelecer limites de gasto e endividamento, mas também abrange o orçamento como um todo ao tratar diretrizes para sua elaboração, execução e avaliação, o que torna o instrumento de controle fiscal mais abrangente já instituído no país.

Desde quando entrou em vigor, os gestores públicos mudaram seu comportamento, ocorrendo uma melhoria na situação das contas públicas. De modo geral, os municípios deixaram de acumular déficits e passaram a ter resultados superavitários. (SANTOLIN; JAIME JR.; REIS, 2009).

Tratando das limitações de gasto público, estabelecidas pela LRF, o controle do gasto com pessoal é uma das verificações realizadas pelos Tribunais de Contas, ao examinar as prestações de contas de governo.

Para Barreto e Mendonça (2010), a despesa com pessoal é um dos maiores dispêndios entre as despesas correntes e, desse modo, deve ser analisada com atenção, propiciando melhor controle dos gastos públicos e do resultado governamental. 
A LRF estabelece um limite global de despesa com pessoal, tanto para os estados quanto também para os municípios. No caso do Poder Executivo municipal, o limite é de $54 \%$ em relação à Receita Corrente Líquida (RCL).

Além desse percentual, a LRF ainda contempla os limites de alerta $(51,30 \%)$ e prudencial $(48,60 \%)$, para os quais os Tribunais de Contas devem alertar os gestores, de modo que possam administrar os gastos com pessoal a fim de não alcançar o limite máximo já citado. Ao final de cada quadrimestre, deve ser feita a verificação desses limites e, caso seja excedido o limite máximo, ou mesmo o prudencial, o Poder fica sujeito a restrições.

Dessa forma, muitas pesquisas buscam fazer o levantamento desses limites e outras vão além, explorando relações com características que possam explicar suas variações nesses percentuais de aplicação da despesa com pessoal em relação à RCL.

\subsection{FATORES QUE IMPACTAM NOS GASTOS COM PESSOAL}

Muitas são as pesquisas que investigam os fatores que influenciam na variação do valor do percentual da despesa com pessoal em relação à RCL, tais como Confessor et al. (2017), Azevedo et al. (2015) e Barreto e Mendonça (2010).

Entre as variáveis identificadas como influentes nesses estudos, podem ser citados o próprio gasto com pessoal, a receita corrente líquida (RCL), a reeleição, a pressão da sociedade, o alinhamento político, além de outros aspectos.

Confessor et al. (2017), observando o comportamento dos municípios paraibanos, destacam a influência significante das regras fiscais e do fato de o prefeito ser aliado político do governador na diminuição dos gastos com pessoal. 
Azevedo et al. (2015) indicam que, nos municípios de São Paulo, a variação no percentual do limite de gasto com pessoal é mais influenciada pela flutuação da despesa com pessoal do que pela receita corrente líquida. Porém, ressaltam que, acima do limite prudencial, esse cenário se inverte.

O estudo de Barreto e Mendonça (2010), ao analisar os determinantes de gastos com despesa com pessoal nos municípios cearenses, concluiu que a pressão da sociedade por bens e serviços públicos, representada pelo tamanho da população, também favorece o aumento desses gastos. Os mesmos autores identificaram que a existência de alinhamento político entre prefeito e governador favorece a redução dos gastos com pessoal. Entre outros aspectos, os autores ainda indicam que a reeleição influencia a redução dos gastos com pessoal no segundo mandato do prefeito reeleito.

A teoria dos ciclos político-econômicos (DOWNS, 1957; NORDHAUS, 1975; ROGOFF, 1990) reforça esse argumento, por indicar que os gastos públicos são maiores no período que antecede à eleição. Esse comportamento pode ser estendido por um período maior quando existe a perspectiva de reeleição. Essa inferência é corroborada pelo resultado da pesquisa de Sakurai e Menezes-Filho (2008), que observaram maiores gastos dos prefeitos durante os seus primeiros mandatos, aumentando as chances de reeleição ou de eleger um sucessor do mesmo partido.

Nessa mesma vertente, Oliveira et al. (2017) identificam que o comportamento do percentual dos gastos com pessoal em relação à RCL de municípios mineiros tem um aumento nos anos anteriores à eleição, mantido nos anos imediatamente seguintes, indicando influência do processo eleitoral nesses gastos, o que confirma uma atitude oportunista dos gestores públicos.

Kutianski e Scarpin (2014) também observaram que o volume de gastos com pessoal é impulsionado positivamente no ano eleitoral nos municípios da região Sul do Brasil. 
Entretanto, é preciso considerar ainda que os chefes do Poder Executivo estão sujeitos a deixar seus mandatos prematuramente por motivos diversos, entre eles a cassação de mandato, sendo que a maioria desses casos é ocasionada por ato de improbidade administrativa e infração eleitoral, segundo a Confederação Nacional de Municípios - CNM (2013). Dessa forma, a mudança prematura do gestor municipal pode ser motivada por irregularidades cometidas na gestão do prefeito anterior, inclusive o descumprimento do limite com despesa com pessoal, gerada por uma expansão exacerbada desses gastos.

Assim, o prefeito substituto pode ser mais prudente, reduzindo gastos, bem como pode buscar corrigir possíveis problemas oriundos da gestão anterior.

Por outro lado, com a possibilidade de a despesa com pessoal já estar elevada, por atos da gestão anterior, ou ainda com a expectativa de o prefeito sucessor ser reeleito, pode haver aumento desses gastos, já que o seu controle só viria em mandatos futuros, conforme já observado por Barreto e Mendonça (2010).

Por fim, Amaral, Marino Júnior e Bonacim (2008) apontam que a despesa com pessoal dos municípios paulistas tem uma variação proporcionalmente similar ao número de habitantes e à quantidade de funcionários da prefeitura. Azevedo et al. (2015), já citados, corroboram a conclusão desses autores.

Azevedo (2013) identificou em seus estudos que, nos municípios paulistas, quando o limite de gastos com pessoal previsto pela LRF não era atendido, havia um aumento da quantidade de servidores efetivos e comissionados. Porém, o autor excetua os municípios de pequeno porte, que apresentavam redução na quantidade de servidores comissionados.

A partir dos estudos aqui apresentados, optou-se por verificar a influência das variáveis explicativas relativas à mudança prematura de prefeitos e à proporção de servidores efetivos e comissionados. 


\section{METODOLOGIA}

A partir da análise de conteúdo dos relatórios emanados pelo Tribunal de Contas dos Municípios do Ceará, cujas funções foram incorporadas pelo Tribunal de Contas do Estado do Ceará, foi elaborado um banco de dados contendo o percentual de despesa com pessoal em relação à RCL. Os aludidos relatórios também foram fonte da informação relativa à mudança prematura do prefeito.

Os dados relativos a idade, partido, escolaridade e sexo do prefeito, bem como da ocorrência de reeleição, foram obtidos do IBGE.

As informações relacionadas a transferências correntes e proporção de servidores efetivos e comissionados foram obtidas por meio do SIM (Sistema de Informações Municipais); sistema pelo qual os gestores apresentam suas prestações de contas mensais ao Tribunal de Contas do Estado do Ceará.

Ressalta-se ainda que o modelo de regressão também foi rodado para municípios com intervalos diferenciados no número de habitantes. Por esse motivo, também foram catalogados os números relativos à população, obtidos no Anuário Estatístico do Ceará, pelo Instituto de Pesquisa e Estratégia Econômica do Ceará (IPECE).

Por fim, informa-se que se buscou colher as informações anteriormente citadas para os 184 municípios que compõem o estado do Ceará, para o período de 2013 a 2016, o que resultaria em 736 observações. No entanto, pela falta de alguns dos relatórios emitidos pelo Tribunal de Contas, bem como pela não identificação de algumas das variáveis explicativas para alguns municípios, em exercícios específicos, a base analisada contempla 674 observações.

A base a ser utilizada abarca a variável dependente do modelo trabalhado, a qual se trata do percentual de despesa com pessoal em relação à RCL (DPRCL).

As variáveis independentes dessa pesquisa foram: mudança prematura de prefeito e proporção de servidores efetivos e comissionados. As va- 
riáveis de controle são: reeleição, alinhamento político com o governador, transferências correntes recebidas, além de gênero, escolaridade e idade do prefeito. Pretende-se, portanto, verificar a influência dessas variáveis nas flutuações do percentual de despesas com pessoal em relação à RCL.

A Tabela 1 evidencia um resumo das variáveis independentes ou explicativas sugeridas como condicionantes para modificação do percentual da despesa com pessoal em relação à receita corrente líquida, bem como seus formatos numéricos, suas fontes de dados e médias correspondentes.

Tabela 1 - Resumos das variáveis explicativas

\begin{tabular}{|c|c|c|c|c|}
\hline Variáveis & Indicador & Fonte do dado & Variação & Médias \\
\hline $\begin{array}{l}\text { Mudança prematura } \\
\text { de prefeito (nprefd) }\end{array}$ & Prefeito substituído & $\begin{array}{c}\text { Relatório de Governo } \\
\text { do Tribunal de } \\
\text { Contas }\end{array}$ & $\begin{array}{l}1 \text { - Prefeito substituído } \\
0 \text { - Mandato completo }\end{array}$ & 0,0372 \\
\hline $\begin{array}{c}\text { Proporção de } \\
\text { servidores efetivos } \\
\text { (ppesefe) }\end{array}$ & $\begin{array}{l}\text { Percentual de } \\
\text { efetivos sobre os } \\
\text { servidores ativos } \\
\text { do executivo }\end{array}$ & $\begin{array}{l}\text { SIM - Tribunal de } \\
\text { Contas }\end{array}$ & $\begin{array}{l}\text { Valor obtido pela } \\
\text { divisão entre servidores } \\
\text { efetivos e o total de } \\
\text { servidores municipais }\end{array}$ & 64,657 \\
\hline $\begin{array}{l}\text { Proporção de servi- } \\
\text { dores comissionados } \\
\quad \text { (ppescom) }\end{array}$ & $\begin{array}{l}\text { Percentual de co- } \\
\text { missionados sobre } \\
\text { os servidores ativos } \\
\text { do executivo }\end{array}$ & $\begin{array}{l}\text { SIM - Tribunal de } \\
\text { Contas }\end{array}$ & $\begin{array}{c}\text { Valor obtido pela } \\
\text { divisão entre servido- } \\
\text { res comissionados e } \\
\text { o total de servidores } \\
\text { municipais }\end{array}$ & 11,610 \\
\hline Reeleição (dreeleito) & Prefeito reeleito & IBGE & $\begin{array}{l}1 \text { - Prefeito reeleito } \\
0 \text { - Primeiro mandato }\end{array}$ & 0,245 \\
\hline $\begin{array}{l}\text { Idade do prefeito } \\
\text { (idade_pref) }\end{array}$ & Idade do prefeito & IBGE & $\begin{array}{l}\text { Valor obtido por } \\
\text { prefeito }\end{array}$ & 47,645 \\
\hline $\begin{array}{l}\text { Gênero do prefeito } \\
\text { (dprefmulher) }\end{array}$ & Gênero do prefeito & IBGE & $\begin{array}{l}1-\text { Mulher } \\
0-\text { Homem }\end{array}$ & 0,18 \\
\hline $\begin{array}{l}\text { Prefeito com ensino } \\
\text { médio (pmedio } \\
\text { comp) }\end{array}$ & $\begin{array}{l}\text { Escolaridade do } \\
\text { prefeito }\end{array}$ & IBGE & $\begin{array}{c}1 \text { - Possui até o Ensino } \\
\text { Médio } \\
0-\text { De outra forma }\end{array}$ & 0,337 \\
\hline $\begin{array}{l}\text { Prefeito com ensino } \\
\text { superior (psuperior) }\end{array}$ & $\begin{array}{l}\text { Escolaridade do } \\
\text { prefeito }\end{array}$ & IBGE & $\begin{array}{c}1 \text { - Possui até o Ensino } \\
\text { Superior } \\
0-\text { De outra forma }\end{array}$ & 0,587 \\
\hline
\end{tabular}


Tabela 1 - Resumos das variáveis explicativas (continuação)

\begin{tabular}{c|c|c|c|c}
\hline Variáveis & Indicador & Fonte do dado & Variação & Médias \\
\hline $\begin{array}{c}\text { Alinhamento políti- } \\
\text { co com o governa- } \\
\text { dor (dpart_gov) }\end{array}$ & $\begin{array}{c}\text { Filiação partidária } \\
\text { do prefeito eleito } \\
\text { pertence à coliga- } \\
\text { ção do governador }\end{array}$ & IBGE & $\begin{array}{c}1-\text { Pertence à coligação } \\
\text { do governador } \\
0-\text { Não pertence à coli- } \\
\text { gação do governador }\end{array}$ & 0,456 \\
\hline $\begin{array}{c}\text { Partido da oposição } \\
\text { (partido_PSDB) }\end{array}$ & $\begin{array}{c}\text { Prefeitos eleitos } \\
\text { filiados ao PSDB } \\
\text { (partido da opo- } \\
\text { sição) }\end{array}$ & IBGE & $\begin{array}{c}1-\text { Prefeito filiado ao } \\
\text { PSDB }\end{array}$ & 0,066 \\
\hline $\begin{array}{c}\text { Transferências cor- } \\
\text { rentes (transflm) }\end{array}$ & $\begin{array}{c}\text { Transfereito não filiado } \\
\text { correntes recebidas } \\
\text { pelos municípios }\end{array}$ & $\begin{array}{c}\text { SIM - Tribunal de } \\
\text { Contas }\end{array}$ & $\begin{array}{c}\text { Valor recebido em } \\
\text { transferências correntes } \\
\text { (em milhões de reais) }\end{array}$ & 76,84 \\
\hline
\end{tabular}

Fonte: Elaborada pelos autores (2021).

Com base na observação dessas variáveis ao longo dos quatro anos estudados, associando-as com a variável dependente já comentada, utilizou-se o modelo com dados agrupados/empilhados para estabelecer as relações entre as variáveis. O seguinte modelo empírico foi adotado:

DPRCL $=\alpha 0+\beta 1($ nprefd it $)+\beta 2($ ppesefe it $)+\beta 3($ ppescom it $)+$ $\beta 4($ dreeleito it $)+\beta 5$ (idade_prefit) $+\beta 6($ dprefmulher it $)+\beta 7$ (pmedio_ comp it $)+\beta 8($ psuperior it $)+\beta 9($ dpart_gov it $)+\beta 10($ partido_PSDB it $)+$ $\beta 11($ transflm it $)+\varepsilon$ it

Desse modo, foi realizada uma estimação com variância de cluster, corrigindo as heterocedasticidades, visto que na base de dados um mesmo município está se repetindo e, com isso, os seus erros se correlacionam.

Acrescenta-se que esse mesmo modelo foi rodado entre municípios com intervalos diferenciados de habitantes, conforme especificado a seguir: i) municípios com menos de 20 mil habitantes; ii) municípios entre 20 mil e 50 mil habitantes; iii) municípios acima de 50 mil habitantes.

$\mathrm{Na}$ Tabela 2, é possível visualizar as flutuações do percentual da despesa com pessoal nos municípios em cada ano, separadamente: 
Tabela 2 - Distribuição dos municípios de acordo com o percentual da despesa com pessoal em relação à RCL

\begin{tabular}{c|c|c|c|c|c}
\hline LIMITE & $\mathbf{\%}$ & $\mathbf{2 0 1 3}$ & $\mathbf{2 0 1 4}$ & $\mathbf{2 0 1 5}$ & $\mathbf{2 0 1 6}$ \\
\hline Limite máximo & Acima de $54 \%$ & $35,52 \%$ & $32,60 \%$ & $39,08 \%$ & $33,33 \%$ \\
\hline $\begin{array}{c}\text { Limite prudencial (95\% do } \\
\text { máximo) }\end{array}$ & Entre 54\% e 51,30\% & $39,89 \%$ & $33,70 \%$ & $35,06 \%$ & $28,93 \%$ \\
\hline $\begin{array}{c}\text { Abaixo do limite pruden- } \\
\text { cial (95\% do máximo) }\end{array}$ & Abaixo de $51,30 \%$ & $24,59 \%$ & $33,70 \%$ & $25,86 \%$ & $37,74 \%$ \\
\hline
\end{tabular}

Fonte: Elaborada pelos autores (2021).

Diante do exposto, observa-se que, entre os exercícios examinados, 2015 foi o ano em que mais municípios excederam o limite máximo de despesa com pessoal disposto pela LRF e, em 2014, o período de menor ocorrência.

Acrescenta-se que, considerando conjuntamente os quatro exercícios examinados, o percentual da despesa com pessoal em relação à RCL, em média, foi de 53,36\%, estando abaixo do limite máximo, mas dentro do limite prudencial.

\section{ANÁLISE DOS RESULTADOS ECONOMÉTRICOS}

Os resultados da estimação do modelo para todos os municípios e para subgrupos populacionais estão expostos na Tabela 3. A primeira coluna de resultados refere-se ao resultado geral.

Tabela 3 - Resultados dos modelos econométricos para percentual de gastos com pessoal, por tamanho do município no Ceará

\begin{tabular}{c|c|c|c|c}
\hline Variáveis & $\begin{array}{c}\text { Todos os } \\
\text { municípios }\end{array}$ & $\begin{array}{c}\text { Abaixo de } \\
\mathbf{2 0} \text { mil hab. }\end{array}$ & $\begin{array}{c}\text { Entre 20 mil e } \\
\mathbf{5 0} \text { mil hab. }\end{array}$ & $\begin{array}{c}\text { Acima de } \\
\mathbf{5 0} \text { mil hab. }\end{array}$ \\
\hline \multirow{2}{*}{ Nprefd } & 2.766 & 5.434 & 2.810 & -1.607 \\
& $(1.238)^{*}$ & $(1.325)^{* *}$ & $(1.549)+$ & $(2.979)$ \\
\hline \multirow{2}{*}{ Ppesefe } & 0.041 & 0.047 & 0.032 & 0.001 \\
& $(0.015)^{* *}$ & $(0.025)+$ & $(0.028)$ & $(0.037)$ \\
\hline
\end{tabular}


Tabela 3 - Resultados dos modelos econométricos para percentual de gastos com pessoal, por tamanho do município no Ceará (continuação)

\begin{tabular}{|c|c|c|c|c|}
\hline Ppescom & $\begin{array}{c}0.008 \\
(0.036)\end{array}$ & $\begin{array}{c}0.023 \\
(0.040)\end{array}$ & $\begin{array}{c}0.019 \\
(0.078)\end{array}$ & $\begin{array}{c}-0.231 \\
(0.067)^{* *}\end{array}$ \\
\hline Variáveis & $\begin{array}{c}\text { Todos os } \\
\text { municípios }\end{array}$ & $\begin{array}{l}\text { Abaixo de } \\
20 \text { mil hab. }\end{array}$ & $\begin{array}{l}\text { Entre } 20 \text { mil e } \\
50 \text { mil hab. }\end{array}$ & $\begin{array}{c}\text { Acima de } \\
50 \text { mil hab. }\end{array}$ \\
\hline Dreeleito & $\begin{array}{c}-3.293 \\
(0.852)^{* *}\end{array}$ & $\begin{array}{c}-3.290 \\
(1.064)^{* *}\end{array}$ & $\begin{array}{l}-2.023 \\
(1.574)\end{array}$ & $\begin{array}{l}-3.938 \\
(3.115)\end{array}$ \\
\hline idade_pref & $\begin{array}{c}0.061 \\
(0.032)^{+}\end{array}$ & $\begin{array}{c}0.100 \\
(0.063)\end{array}$ & $\begin{array}{c}0.044 \\
(0.038)\end{array}$ & $\begin{array}{c}0.053 \\
(0.048)\end{array}$ \\
\hline Dprefmulher & $\begin{array}{c}-1.679 \\
(0.986)+\end{array}$ & $\begin{array}{c}-0.774 \\
(1.240) \\
\end{array}$ & $\begin{array}{l}-3.417 \\
(2.393)\end{array}$ & $\begin{array}{c}-2.743 \\
(1.469)+\end{array}$ \\
\hline pmedio_comp & $\begin{array}{c}0.434 \\
(1.339)\end{array}$ & $\begin{array}{l}-0.025 \\
(2.191)\end{array}$ & $\begin{array}{c}1.354 \\
(1.457)\end{array}$ & $\begin{array}{c}1.331 \\
(1.329)\end{array}$ \\
\hline Psuperior & $\begin{array}{c}0.082 \\
(1.295)\end{array}$ & $\begin{array}{l}-0.327 \\
(2.128)\end{array}$ & $\begin{array}{c}1.570 \\
(1.105)\end{array}$ & \\
\hline part_gov & $\begin{array}{c}0.188 \\
(0.672)\end{array}$ & $\begin{array}{c}0.990 \\
(0.966)\end{array}$ & $\begin{array}{c}0.056 \\
(1.260)\end{array}$ & $\begin{array}{l}-1.081 \\
(1.225)\end{array}$ \\
\hline partido_PSDB & $\begin{array}{l}1.063 \\
(1.442)\end{array}$ & $\begin{array}{l}1.426 \\
(1.999)\end{array}$ & $\begin{array}{l}1.444 \\
(1.407)\end{array}$ & $\begin{array}{l}-0.093 \\
(2.987)\end{array}$ \\
\hline transf1m & $\begin{array}{c}-0.003 \\
(0.001)^{* *}\end{array}$ & $\begin{array}{c}0.077 \\
(0.049)\end{array}$ & $\begin{array}{c}-0.062 \\
(0.037)^{+}\end{array}$ & $\begin{array}{c}-0.002 \\
(0.001)^{* *}\end{array}$ \\
\hline 2014bn.ano & $\begin{array}{c}-0.925 \\
(0.320)^{* *}\end{array}$ & $\begin{array}{c}-1.204 \\
(0.602)^{*}\end{array}$ & $\begin{array}{l}-0.336 \\
(0.527)\end{array}$ & $\begin{array}{c}-1.261 \\
(0.662)^{+}\end{array}$ \\
\hline 2015.ano & $\begin{array}{l}-0.141 \\
(0.459)\end{array}$ & $\begin{array}{l}-0.313 \\
(0.839)\end{array}$ & $\begin{array}{c}0.003 \\
(0.810)\end{array}$ & $\begin{array}{c}0.098 \\
(0.973)\end{array}$ \\
\hline 2016.ano & $\begin{array}{c}-1.385 \\
(0.474)^{* *}\end{array}$ & $\begin{array}{c}-1.867 \\
(0.867)^{*}\end{array}$ & $\begin{array}{l}-1.261 \\
(0.947)\end{array}$ & $\begin{array}{l}-0.189 \\
(0.984)\end{array}$ \\
\hline Constant & $\begin{array}{c}49.060 \\
(2.384)^{* *}\end{array}$ & $\begin{array}{c}44.499 \\
(3.994)^{* *}\end{array}$ & $\begin{array}{c}52.199 \\
(4.668)^{* *}\end{array}$ & $\begin{array}{c}54.346 \\
(3.191)^{* *}\end{array}$ \\
\hline $\mathbf{R}^{2}$ & 0.12 & 0.15 & 0.15 & 0.29 \\
\hline $\begin{array}{l}\text { Número de } \\
\text { observações }\end{array}$ & 674 & 310 & 237 & 127 \\
\hline
\end{tabular}

+ Significante a $10 \%$; * Significante a 5\%; ** Significante a 1\%. Desvio padrão robusto para cluster de município entre parênteses

Fonte: Elaborada pelos autores (2021).

Entre as variáveis explicativas examinadas, algumas se mostraram 
não significantes para justificar a variação do percentual de despesa com pessoal. Uma delas foi a proporção de servidores comissionados (ppescom). Tal fato pode ser explicado pela baixa representatividade dos servidores comissionados $(11,61 \%$, em média) quando comparado com os servidores efetivos $(64,66 \%$, em média $)$, que foi significante.

No tocante à proporção de servidores efetivos, verificou-se que o aumento da proporção destes ocasiona um aumento de 0,041 no percentual de gasto com pessoal em relação à receita corrente líquida. Tal resultado segue as conclusões de Amaral, Marino Júnior e Bonacim (2008), Azevedo (2013) e Azevedo et al. (2015), corroborando a expectativa de correlação positiva. Esse resultado pode ser explicado pelo fato de que, normalmente, os salários dos servidores efetivos são maiores em comparação aos dos estagiários e demais prestadores de serviços.

Em relação à mudança prematura de prefeito, constata-se a influência positiva de 2,77 no percentual de despesa com pessoal (DPRCL), ratificando o entendimento disposto no referencial teórico, isto é, ou a despesa com pessoal já está elevada, por atos da gestão anterior, ou a expectativa do prefeito sucessor de ser reeleito ocasionou o aumento desses gastos e o seu controle só virá em mandatos futuros do recém-empossado.

Em relação às variáveis de controle, observa-se que, nos municípios onde se contemplam prefeitos reeleitos, ocorre uma redução de 3,29 no percentual de despesa com pessoal (DPRCL), reforçando o estudo de Barreto e Mendonça (2010), que também avaliou a influência dessa variável, nos municípios cearenses, para o período de 1998 a 2008.

$\mathrm{O}$ fato de os gastos municipais com pessoal serem maiores nos anos que antecedem as eleições caracteriza um comportamento oportunista dos gestores públicos municipais, explicado pela teoria dos ciclos político-econômicos (SAKURAI; MENEZES-FILHO, 2008; OLIVEIRA et al., 2017; KUTIANSKI; SCARPIN, 2014).

Quanto à escolaridade do prefeito, o fato de ter Ensino Superior ou 
Ensino Médio não foi significante para explicar a variação do percentual da despesa com pessoal em relação à receita corrente líquida (DPRCL).

Da mesma forma, ao se avaliar a influência do alinhamento político do prefeito com o governador do estado, bem como a filiação do prefeito em partido da oposição (PSDB), não foi observada sua significância para explicar a flutuação da variável dependente em análise. Dessa forma, não se confirmou o apurado nas pesquisas de Barreto e Mendonça (2010) e Confessor et al. (2017), nas quais foi indicada significância e uma redução dos gastos com pessoal.

Todavia, as variáveis idade e gênero do prefeito se demonstraram capazes de explicar a variação do percentual da despesa com pessoal. Verifica-se que, à medida que aumenta um ano na idade do prefeito, ocorre um aumento de 0,061 desse percentual. Já no caso de o prefeito ser do sexo feminino, verifica-se a redução de 1,68 no percentual.

No que tange às transferências correntes, a cada milhão de reais recebido ocorre uma redução de 0,003 no percentual de despesa com pessoal (DPRCL), fato que pode ser justificado pelo aumento da receita corrente líquida gerado pelo ingresso desse recurso.

Ao se fazer uma análise estratificada, por número de habitantes dos municípios, é possível verificar que os resultados qualitativos, encontrados no modelo geral, são também observados no modelo para municípios menores (abaixo de 20 mil habitantes), com exceção de idade e gênero do prefeito e transferências correntes recebidas, fatores que não se demonstraram significantes para explicar a variação do percentual de despesa com pessoal em municípios com essa faixa de habitantes.

Essa similaridade pode ser explicada pelo fato de a maioria dos municípios analisados se encontrar nesse intervalo de número de habitantes.

Em contrapartida, nos municípios com população de 20 a 50 mil habitantes, entre as variáveis explicativas, apenas a mudança prematura de prefeito se manteve significante, como também a variável de controle e transferências correntes recebidas. 
Nos municípios com mais de 50 mil habitantes, entre as variáveis consideradas significantes para todos os municípios examinados, apenas gênero do prefeito e transferências correntes recebidas mantiveram esse patamar; dessa forma, nenhuma das variáveis explicativas se mostraram significantes. Em contrapartida, o percentual de cargos comissionados, que não tinha valor explicativo quando se analisa os municípios como um todo, mostrou-se significante nesse recorte (mais de 50 mil hab.) dos municípios, influenciando negativamente. A existência de cargos comissionados em maior quantidade, em municípios de maior porte, e com remuneração menor do que a dos efetivos, pode justificar essa última consideração. Portanto, verifica-se que as características educacionais e partidárias permaneceram sem se mostrar significantes, independentemente do porte dos municípios.

Ressalte-se, por fim, que os resultados identificados nesta pesquisa corroboram achados de estudos anteriores, com destaque para a consolidação do entendimento emanado na teoria dos ciclos político-econômicos, evidenciando que o gestor dos recursos públicos tende a conter mais os gastos em seu segundo mandato.

\section{CONCLUSÃO}

O presente trabalho busca investigar como a composição dos funcionários municipais (efetivos, comissionados, estagiários, prestação de serviços) e uma eventual mudança de prefeito ao longo do interstício administrativo afetam os gastos com pessoal como proporção da receita corrente líquida dos municípios do estado do Ceará.

$\mathrm{O}$ aumento de tal percentual pode ensejar o descumprimento de dispositivo legal supervisionado por órgão de controle externo estadual, Tribunais de Contas, responsáveis por observar a regular aplicação dos recursos públicos desses entes subnacionais.

Os resultados denotam que aspectos políticos são significantes para 
explicar as variações no percentual de despesa com pessoal, sendo que a mudança prematura de prefeito influencia para o aumento desse número, levando a crer que prefeitos substitutos não tendem a promover ajustes de pessoal; pelo contrário, aumentam ainda mais o percentual da despesa com pessoal sobre a RCL, com riscos maiores de irregularidades.

Quanto à composição do quadro de funcionários das prefeituras, somente o percentual de servidores efetivos, em relação ao montante de funcionários do Poder Executivo do município, foi significante ao analisar todos os municípios, impactando positivamente na flutuação do percentual. Esse resultado pode ser explicado pelo fato de que normalmente os salários dos servidores efetivos são maiores se comparados com os dos estagiários e demais prestadores de serviços.

Dessa forma, a gestão do limite do percentual com gastos de pessoal deve atentar para o incremento dos servidores efetivos, tendo em vista o impacto que tal variável pode ocasionar.

No tocante às variáveis de controle, a reeleição, o fato de o prefeito ser do gênero feminino e o volume de transferências correntes recebidas colaboram para a redução do percentual. Tal fato não se repete na variável idade do prefeito, que apresentou relação positiva.

No que tange aos municípios com menos de 20 mil habitantes, os resultados se repetem, com exceção de idade e gênero do prefeito, e transferências correntes recebidas, os quais não se demonstraram significantes nesse caso.

Nos municípios com população de 20 a 50 mil habitantes, apenas a mudança prematura de prefeito e transferências correntes recebidas se mantiveram significantes.

Nos municípios com mais de 50 mil habitantes, o gênero do prefeito e as transferências correntes recebidas se mostraram significantes. Por outro lado, o percentual de cargos comissionados, que até então não tinha valor explicativo, mostrou-se significante nesse recorte dos municípios, influenciando negativamente. A existência de cargos comissionados em 
maior quantidade, em municípios de maior porte e com remuneração menor do que a dos efetivos, pode justificar essa última consideração.

No caso da escolaridade do prefeito e do alinhamento político do governador, não se mostraram significantes em nenhum dos âmbitos examinados.

É importante ressaltar que as limitações desse trabalho englobam a questão temporal, tendo em vista que contemplou apenas um mandato de prefeito e a base de dados, tendo em vista que as informações sobre o percentual de gastos com pessoal foram colhidas a partir de relatórios emanados pelo Tribunal de Contas, sendo que alguns desses relatórios ainda não tinham sido elaborados.

Por fim, sugerem-se novas pesquisas buscando identificar outras variáveis que possam explicar as alterações do percentual da despesa com pessoal em relação à receita corrente líquida, analisando a influência do valor específico dos salários dos funcionários atentando para o tamanho dos municípios, bem como replicar essa pesquisa entre municípios de outros estados.

\section{REFERÊNCIAS}

ALVES, J. A.; FREITAS, M. R. O.; OLIVEIRA, L. G. L. A análise do controle das despesas com pessoal no Poder Judiciário: um estudo aplicado aos Tribunais de Justiça de médio porte. Revista Controle, Fortaleza, v. 13, n. 2, 2015. Disponível em: http://revistacontrole.ipc.tce.ce.gov.br/ index.php/RCDA/article/view/3. Acesso em: 23 maio 2018.

AMARAL, P. F.; JÚNIOR, J. M.; BONACIM, C. A. G. Contabilidade governamental: uma análise da implementação da lei de responsabilidade fiscal em municípios paulistas. Revista de Contabilidade do Mestrado em Ciências Contábeis da UERJ, Rio de Janeiro, v. 13, n. 1, p. 1-15, 2008.

AZEVEDO, R. R. Uma análise dos índices da lei de responsabilidade fiscal nos municípios paulistas após a implantação do projeto AUDESP: Revista 
de Gestão, Finanças e Contabilidade, Salvador, v. 3, n. 2, p. 39-60, 2013.

AZEVEDO, R. R.; GATSIOS, R. C.; SILVA, J. M. da; LIMA, F. G. Determinantes da variação do limite de gastos com pessoal em municípios paulistas. Revista Ambiente Contábil, Natal, UFRN, v. 7, n. 1, p. 216232, jan./jun. 2015. Disponível em: https://periodicos.ufrn.br/ambiente/ article/view/5591. Acesso em: 23 maio 2019.

BARRETO, F. A. F. D.; MENDONÇA, H. H. M. Uma investigação sobre os determinantes dos gastos com pessoal e Lei de Responsabilidade Fiscal nos municípios nordestinos. Cad. Fin. Públ., Brasília, n. 10, p. 175-193, dez. 2010.

CNM. Pesquisa da CNM mostra que 383 prefeitos já perderam o mandato. Estudos Técnicos, Brasília, CNM, v. 5, n. 23, p. 234-236, 2013. Disponível em: http://www.cnm.org.br/cms/biblioteca_antiga/ET\%20Vol\%20 5\%20-\%2023.\%20Pesqisa $\% 20$ da $\% 20$ CNM $\% 20$ mostra $\% 20 q u e \% 20$ $383 \% 20$ prefeitos\%20já\%20perderam\%20o\%20mandato.pdf.

CONFESSOR, K. L. A.; COSTA, J. M. da; TORRES, A. R. L. E.; TORRES, F. J. V. Despesas com pessoal nos municípios do estado da Paraíba: uma análise do último triênio (2014 a 2016). In: XX SEMEAD - SEMINÁRIOS EM ADMINISTRAÇÃO, São Paulo, SP, Brasil, novembro de 2017. Disponível em: http://login.semead.com.br/20semead/anais/arquivos/2154.pdf. Acesso em: 9 jun. 2019.

CRISÓSTOMO, V. L.; CAVALCANTE, N. S. C.; FREITAS, A. R. M. C. A LRF no trabalho de controle de contas públicas - um estudo de pareceres prévios conclusivos de contas de governos municipais. Revista Ambiente Contábil, Natal, UFRN, v. 7, n. 1, p. 233-253, jan./jun. 2015.

CRUZ, C. F. da; MACEDO, M. A. S.; SAUERBRONN, F. F. Responsabilidade fiscal de grandes municípios brasileiros: uma análise de suas 
características. Revista de Administração Pública, [s. l.], v. 47, n. 6, p. 1375-1400, 2013.

DOWNS, A. Economic theory of political action in a democracy. Journal of Political Economy, v. 65, n. 2, apr., 1957.

GIUBERTI, A. C. Efeitos da lei de responsabilidade fiscal sobre os gastos dos municípios brasileiros. 2005. 61 f. Dissertação (Mestrado) - Faculdade de Economia, Administração e Contabilidade, Universidade de São Paulo, São Paulo, 2005. Disponível em: http://www.teses.usp.br/ teses/disponiveis/12/12138/tde-06052005-160301/pt-br.php. Acesso em: 23 maio 2018.

JENSEN, M. C.; MECKLING, W. H. Theory of the firm: managerial behavior, agency costs and ownership structure. Journal of Financial Economics, [s. l.], v. 3, n. 4, 1976.

KRUGER, G. P.; KRONBAUER, A.; SOUZA, M. A. de. Análise dos fatores explicativos de inconformidade apontadas pelo TCE/RS em auditorias municipais. Revista Contexto, Porto Alegre, v. 12, n. 22, p. 43-58, $2^{\circ}$ semestre 2012.

KUTIANSKI, S.; SCARPIN, J. E. Influência dos ciclos eleitorais na política fiscal dos municípios da região sul do Brasil: uma análise para o período de 2003-2012 via dados em painel. XXXVIII ENCONTRO DA ANPAD, Rio de Janeiro, set. 2014.

NORDHAUS, W. The political business cycle. Review of Economic Studies, [s. 1.], v. 42, p. 169-190, 1975.

OLIVEIRA, K. F.; NOGUEIRA, L. R. T.; CARÍSSIMO, C. R.; CURI, M. A.; RESENDE, L. L. O processo eleitoral municipal interfere no gasto com pessoal? XX SEMEAD - SEMINÁRIOS EM ADMINISTRAÇÃO, 
São Paulo, SP, Brasil, novembro de 2017. Disponível em: http://login.semead.com.br/20semead/anais/arquivos/681.pdf. Acesso em: 9 jul. 2019. ROGOFF, K. Equilibrium political budget cycles. The American Economic Review, [s. l.], v. 80, p. 21-26, 1990.

SAKURAI, S. N.; MENEZES-FILHO, N. A. Fiscal policy and reelection in Brazilian municipalities. Public Choice, [s. l.], v. 137, p. 301-314, 2008.

SANTOLIN, R.; JAYME JR., F. G.; REIS, J. C. Lei de Responsabilidade Fiscal e implicações na despesa de pessoal e de investimento nos municípios mineiros: um estudo com dados em painel dinâmico. Est. Econ., São Paulo, v. 39, n. 4, p. 895-923, out./dez. 2009.

SILVA, L. H. Despesas com pessoal de acordo com a Lei de Responsabilidade Fiscal no município de Camboriú/SC. XXI SEMEAD - SEMINÁRIOS EM ADMINISTRAÇÃO, São Paulo, SP, Brasil, novembro de 2018. Disponível em: http://login.semead.com.br/21 semead/anais/arquivos/2320.pdf. Acesso em: 9 jul. 2019.

SLOMSKI, V. Controladoria e governança na gestão pública. São Paulo: Atlas, 2009. 